This item was submitted to Loughborough's Institutional Repository (https://dspace.lboro.ac.uk/) by the author and is made available under the following Creative Commons Licence conditions.

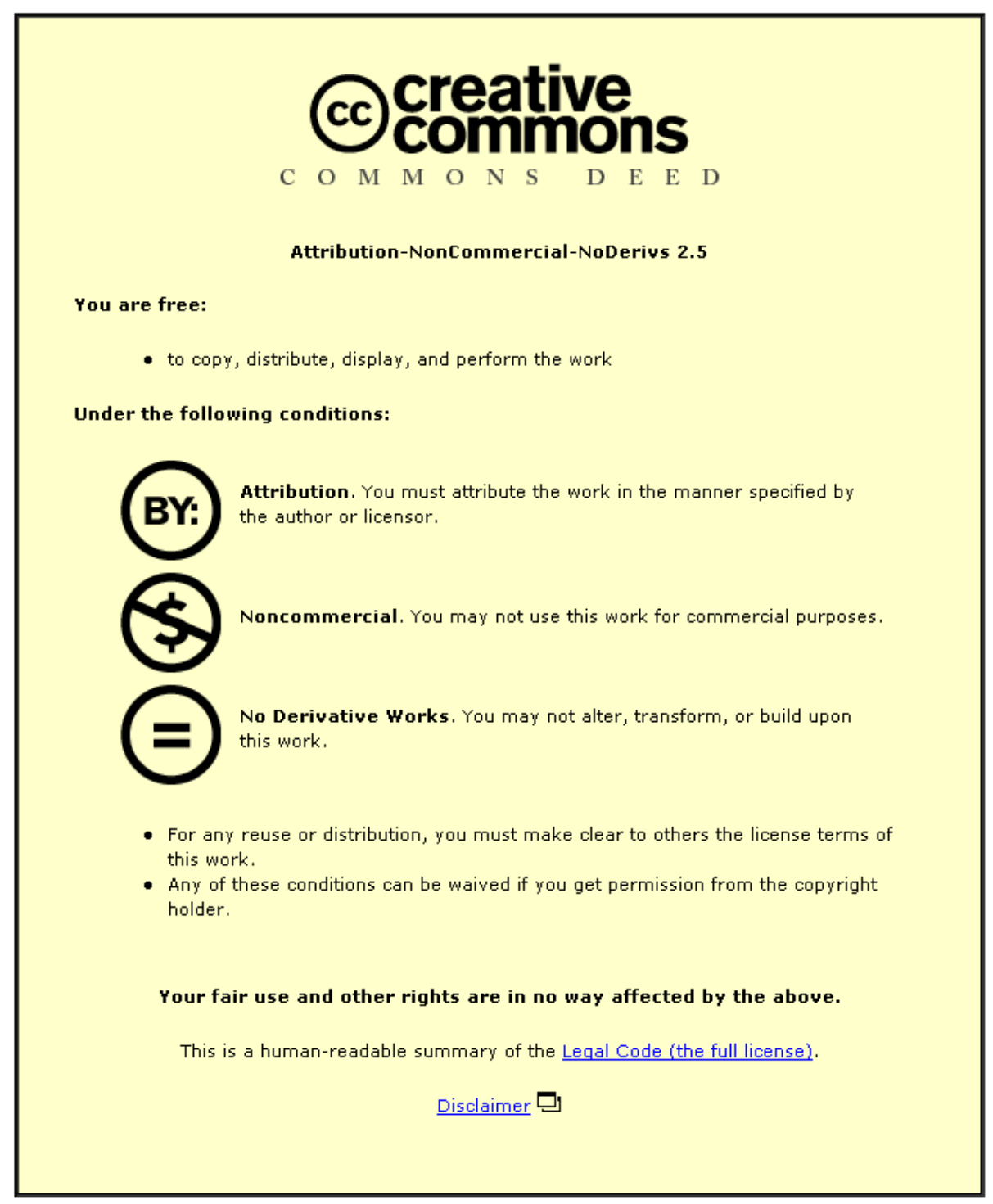

For the full text of this licence, please go to: http://creativecommons.org/licenses/by-nc-nd/2.5/ 


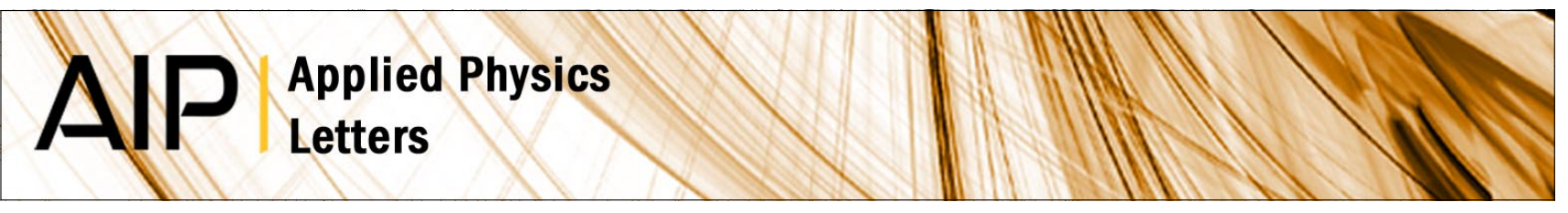

The penetration limit of poly(4-vinyl phenol) thin films for etching via holes by inkjet printing

Y. Zhang, C. Liu, and D. C. Whalley

Citation: Appl. Phys. Lett. 101, 253302 (2012); doi: 10.1063/1.4772796

View online: http://dx.doi.org/10.1063/1.4772796

View Table of Contents: http://apl.aip.org/resource/1/APPLAB/v101/i25

Published by the American Institute of Physics.

\section{Related Articles}

TiO2 nanoparticles and silicon nanowires hybrid device: Role of interface on electrical, dielectric, and photodetection properties

Appl. Phys. Lett. 101, 253104 (2012)

Strain relaxation in $\mathrm{GaN}$ nanopillars

Appl. Phys. Lett. 101, 253102 (2012)

Statistically modified surfaces: Experimental solutions for controlled scattered light

J. Appl. Phys. 112, 114325 (2012)

Digging up bulk band dispersion buried under a passivation layer

Appl. Phys. Lett. 101, 242103 (2012)

Influence of surface tension on cavitation noise spectra and particle removal efficiency in high frequency ultrasound fields

J. Appl. Phys. 112, 114322 (2012)

\section{Additional information on Appl. Phys. Lett.}

Journal Homepage: http://apl.aip.org/

Journal Information: http://apl.aip.org/about/about_the_journal

Top downloads: http://apl.aip.org/features/most_downloaded

Information for Authors: http://apl.aip.org/authors

\section{ADVERTISEMENT}

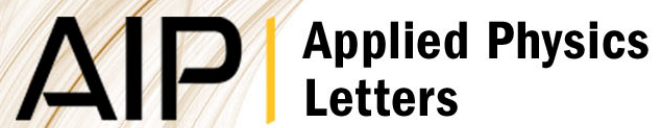

\section{EXPLORE WHAT'S NEW IN APL}

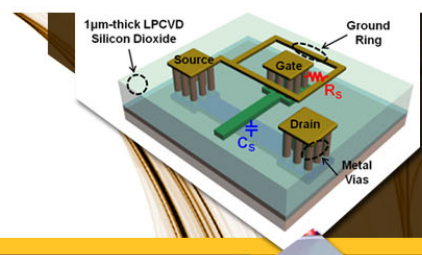

SURFACES AND INTERFACES

Focusing on physical, chemical, biological, structural, optical, magnetic and electrical properties of surfaces and interfaces, and more.. 


\title{
The penetration limit of poly(4-vinyl phenol) thin films for etching via holes by inkjet printing
}

\author{
Y. Zhang (张岩), C. Liu, ${ }^{\text {a) }}$ and D. C. Whalley \\ Wolfson School of Mechanical and Manufacturing Engineering, Loughborough University, Loughborough, \\ Leicestershire LE11 3TU, United Kingdom
}

(Received 8 July 2012; accepted 5 December 2012; published online 19 December 2012)

\begin{abstract}
This paper reports the penetration limit of via holes through dissolving dielectric polymer thin films by inkjet printing. It was found that both the outer diameter of via holes and the polymer thickness affect the penetration depth from the experimental results. Based on this finding, a more accurate relationship between the inner diameter of via holes and the diameter of in-flight droplets for different polymer thicknesses is obtained. (C) 2012 American Institute of Physics. [http://dx.doi.org/10.1063/1.4772796]
\end{abstract}

Inkjet patterning has received significant attention to enable various applications such as microlenses, ${ }^{1,2}$ displays, ${ }^{3,4}$ transistors, ${ }^{5-8}$ conductive structures, ${ }^{9,10}$ organic photovoltaics, ${ }^{11}$ and all-printed organic electronics ${ }^{12}$ in the past decade. One of those applications is to use it as an etching technique to dissolve holes in polymer materials for vertical connection. Xia and Friend ${ }^{4}$ and Lu et al. ${ }^{13}$ showed in their experiments that bank arrays could be fabricated by inkjet as patterned structures in display applications. Yang et al. ${ }^{14}$ demonstrated using Ag ink with etching solvent to form the path by permeating poly(methyl methacrylate) (PMMA) and filling it simultaneously. Kawase et al. ${ }^{15,16}$ etched via holes in a polymer dielectric layer for interconnection using inkjet printing for making all plastic transistor circuits, owing to the coffee ring effect, during which materials loaded in solvents are carried to the contact line. ${ }^{17-19}$ de Gans et al. ${ }^{20,21}$ demonstrated arrays of holes of different shapes in polystyrene using inkjet-printed drops. Xia and Friend $^{4,22}$ observed a thin polymer layer at the bottom of these holes after solvent evaporation and reported its removal by continuous solvent deposition. Kawase et al. ${ }^{16}$ and Zhang et al., ${ }^{23}$ respectively, employed inkjet-printed test structures and electroplating technique to demonstrate that the holes could be etched through thoroughly. Up to date, investigations have been mainly focused on the relationships between printing parameters such as drop numbers and frequencies and via hole dimensions including diameters and hole depth. ${ }^{16,20,21,23,24}$ Few have studied the limitation of using inkjet etching to produce via holes in polymer layers. Via hole formation in polymer films by inkjet etching is through polymer dissolution and re-deposition, which is different from etching holes in silicon dioxide reported by Lennon et al., ${ }^{25}$ where chemical reaction is involved and the soluble product can be washed away afterwards in water. Since there is neither local removal of the dissolved polymer from inside the hole nor evaporation of the polymer, the dissolved polymer must re-occupy the space within the produced via hole during re-deposition. Therefore, a limit of penetration depth can be expected, thereby posing a barrier

\footnotetext{
${ }^{\text {a) }}$ Author to whom correspondence should be addressed. Electronic mail: C.Liu@lboro.ac.uk.
}

to making a through via hole. If the polymer layer is not completely etched through, subsequent filling with conductive materials in the holes will result in an electrical failure due to the residual insulating polymer. In this paper, we investigate the polymer penetration limit during the inkjet via hole etching process based on the experimental study. It is envisaged that the results may assist the optimum design of such via holes in microelectronic devices.

Poly(4-vinyl phenol) (PVPh) was dissolved into isopropyl alcohol (IPA) to yield a transparent brown-colored solution, which was spin coated onto a glass substrate subsequently to produce a thin PVPh film. Multiple IPA drops were jetted using a Microfab Jetlab ${ }^{\circledR} 4$ printer onto the PVPh film to dissolve via holes so that no residual polymer existed and the glass substrate was exposed. The via hole dimensions, outer diameter $\left(D_{\text {out }}\right)$, inner diameter $\left(D_{\text {in }}\right)$, and depth $\left(H_{d}\right)$ were measured by scanning the profile using a Zygo ${ }^{\circledR}$ scanning white-light interferometry (SWLI) microscope. Figure 1 shows a typical inkjet-etched via hole that was created in this study and its profile.

The relation between $D_{\text {out }}$ and via hole penetration is investigated using a polymer layer of a fixed thickness, which is approximately $4.5 \mu \mathrm{m}$. Different $D_{\text {out }}$ can then be obtained by changing the droplet diameter using nozzles of different sizes or heating the substrate. Figure 2 presents the relationship between $D_{\text {in }}$ and $D_{\text {out }}$, which can be described by a linear equation, i.e., $D_{\text {in }}=0.4 D_{\text {out }}-17.7$. It should be noted that both $D_{\text {out }}$ and $D_{\text {in }}$ discussed in this paper are of the via holes completely penetrated with the glass substrate being exposed, but not of the intermediate ones which still have polymer residue at the bottom. This is not necessarily important for $D_{\text {out }}$ as it does not change with the number of drops $\left(N_{d}\right)$ dispensed at low frequencies. ${ }^{23}$ However, it is important for $D_{i n}$ as it does vary with $N_{d}$. Therefore, it is the level-off value of $D_{i n}$ when it does not change any more with $N_{d}$ that is being studied here for each $D_{\text {out }}$ and polymer thickness. Due to the nozzle size limit and the low surface tension of IPA, the smallest $D_{\text {out }}$ that could be achieved in this study was $69.8 \mu \mathrm{m}$, where the coated polymer layer was still completely penetrated. However, by extrapolating the linear equation to the intersection $A\left(D_{\text {in }}=0\right)$, we have $D_{\text {out }}=44.3 \mu \mathrm{m}$. This implies that $D_{\text {in }}$ will shrink down to zero when the via hole assumes a 


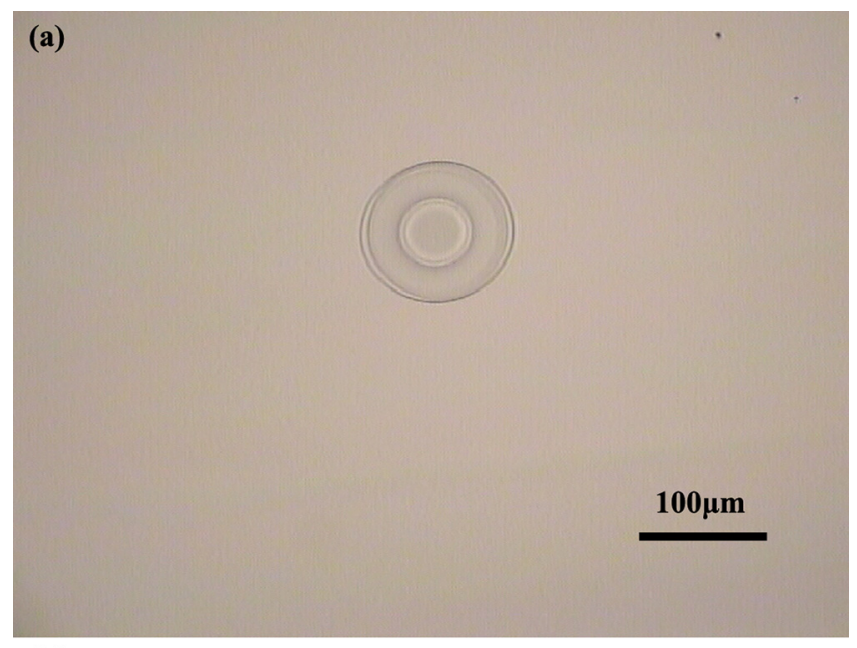

(b)

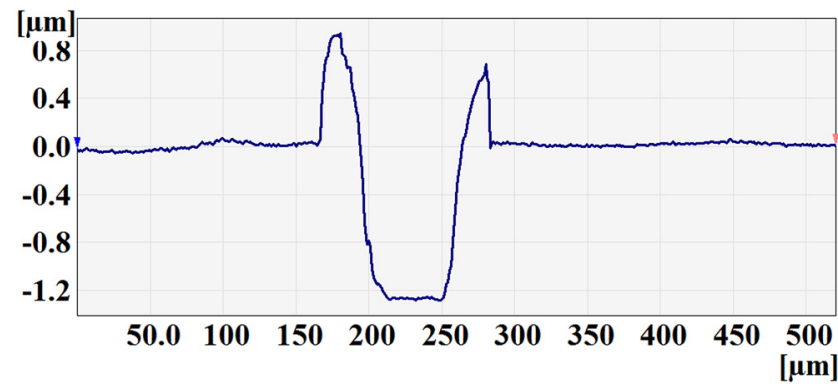

FIG. 1. (a) An optical microscopy image of an inkjet-etched via hole in a PVPh thin film; (b) The profile of a typical inkjet-etched via hole.

$D_{\text {out }}$ of $44.3 \mu \mathrm{m}$ theoretically. Therefore, to penetrate a $4.5 \mu \mathrm{m}$ thick PVPh layer by jetting IPA, the minimum outer diameter $D_{\text {out min }}$ of the via hole should exceed at least $44.3 \mu \mathrm{m}$. If $D_{\text {out }}$ is smaller than $D_{\text {out min }}$, the resulting via hole cannot be penetrated thoroughly through the polymer layer no matter how many drops are dispensed.

The effect of polymer thickness is investigated next using a fixed droplet diameter/volume. A $\Phi 40 \mu \mathrm{m}$ nozzle was used to jet IPA as the etching solvent. The jetted droplet diameter and volume were estimated to be approximately $38.4 \mu \mathrm{m}$ and $29.6 \mathrm{pl}$, respectively. Different polymer thicknesses were achieved by varying the polymer concentration in solutions and the parameters during the spin coating process. Figure 3 illustrates the relationship between $D_{\text {in }}, D_{\text {out }}$, and polymer thickness. It can be clearly observed that $D_{\text {in }}$ decreases with increases of polymer thickness, while $D_{\text {out }}$ stays independent of polymer thickness. Since $D_{\text {out }}$ is primarily determined by drop diameter/volume, it remains constant due to a fixed droplet diameter used in the experiment. $D_{\text {in }}$ decreases rapidly with polymer thickness at the initial stage, but then slowly when the polymer layer becomes thicker. The depth of the produced via hole and the corresponding polymer thickness is in a proportional relationship with the constant of proportionality being 1 , as plotted by the dashed line in Figure 3. This implies that the depth of each via hole created is equivalent to the polymer thickness, which, in turn, indicates complete penetration of the polymer films. Due to the difficulty of further increasing $\mathrm{PVPh}$ thickness because of the internal stress induced, which can cause polymer cracking, the threshold polymer thickness was not found experimentally in this work. Nonetheless, failure to etch through a thick polymer layer by inkjet printing was demonstrated in our previous work using the polyacrylamide/deionized water system. ${ }^{23}$ Therefore, it is postulated that a threshold polymer thickness exists, above which a $38.4 \mu \mathrm{m}$ IPA droplet cannot completely penetrate the PVPh film in spite of the number of drops dispensed.

This via hole formation is believed to comprise three processes: droplet impact and spreading, polymer dissolution, and solvent evaporation. When a droplet lands on the surface, it quickly wets into a sessile drop covering a contact area. The bigger the diameter of the in-flight droplet, the more area it wets when transforming into a sessile drop on the substrate. Therefore, it can be assumed that the in-flight droplet diameter $\left(D_{0}\right)$ can determine the size of the produced via hole. To test the effect of $D_{0}$ on the dimensions of the via holes, IPA drops of various diameters were dispensed onto glass substrates with three different PVPh thicknesses. The droplet ejection frequency was set to $1 \mathrm{~Hz}$ to leave enough time for the previous sessile drop to evaporate substantially so that via holes would not be enlarged with an increasing $N_{d}$. Figure 4 illustrates the effect of in-flight droplet diameter on the size of completed etched via holes produced in $\mathrm{PVPh}$ layers of different thicknesses.

Both $D_{\text {out }}$ and $D_{\text {in }}$ were found to be in linear relationships with $D_{0}$ for each polymer thickness as shown in Figure 4. This finding is in agreement with what Kawase et al. ${ }^{16}$

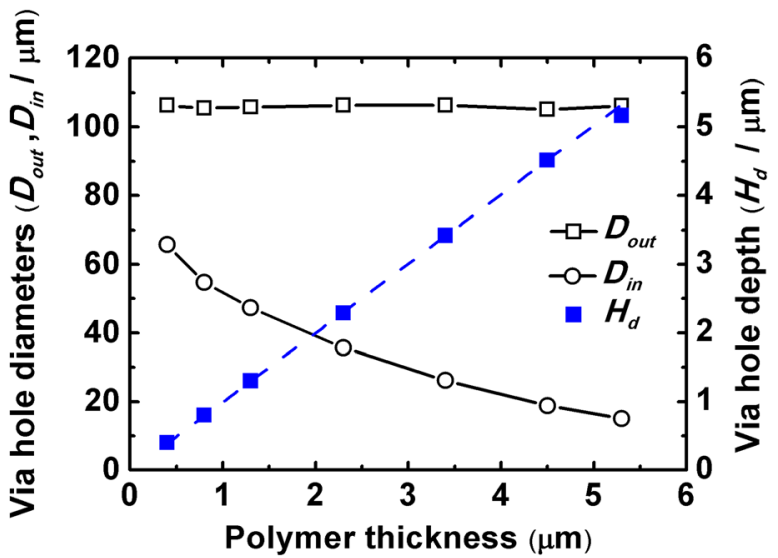

FIG. 3. The profile of $D_{\text {out }}$ and $D_{\text {in }}$ as a function of the polymer thickness.

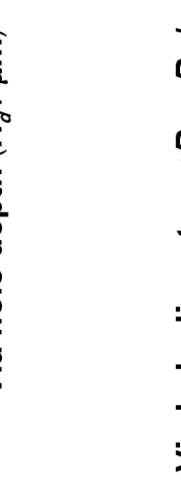

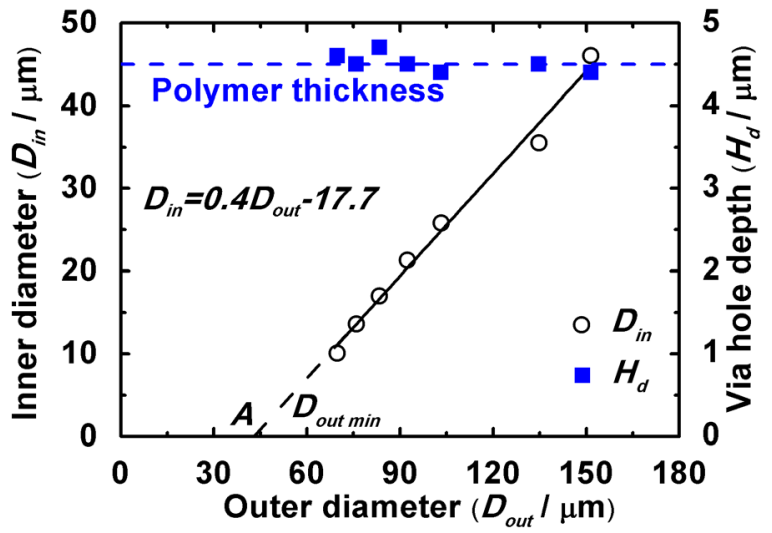

FIG. 2. The profile of $H_{d}$ and $D_{\text {in }}$ as a function of $D_{\text {out }}$. 


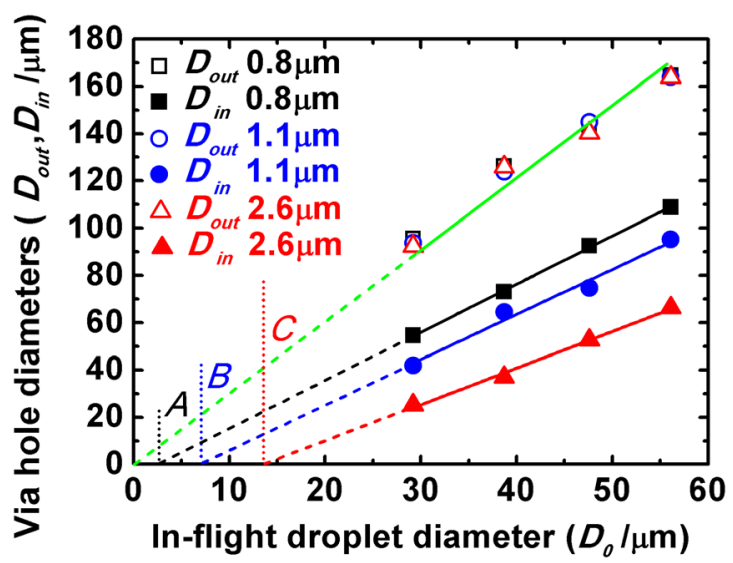

FIG. 4. The profile of $D_{\text {out }}$ and $D_{\text {in }}$ of completely penetrated via holes versus the diameter of the in-flight droplet $\left(D_{0}\right)$ for different polymer thicknesses.

reported in their work. $D_{\text {out }}$ for different polymer thicknesses can be fitted as one single straight line as a function of $D_{0}$. This means that polymer thickness has no effect on $D_{\text {out }}$ as long as the in-flight droplet diameter remains constant. $D_{i n}$ was fitted into individual lines corresponding to different polymer thicknesses because polymer thickness influences the final $D_{i n}$ when the layer is completely penetrated, which has already been shown in Figure 3. As illustrated in Figure 4 , with the same $D_{0}$, the corresponding $D_{i n}$ of the formed via hole is the smallest in the $2.6 \mu \mathrm{m}$ polymer layer and biggest in the $0.8 \mu \mathrm{m}$ polymer layer. Nonetheless, the three individual straight lines representing $D_{i n}$ versus $D_{0}$ are fit to have different intersections with the $D_{0}$ axis, not intersecting at one point according to Kawase et al. ${ }^{16}$ The intersection refers to a minimum required amount of dispensed solvent for completely etching through the polymer layer $\left(D_{i n}=0\right)$. The thicker the polymer layer, the more polymer must be removed by the droplet, and the larger it must be. Therefore, $D_{\text {out min }}$ obtained via the extrapolation to $D_{\text {in }}=0$ shifts to larger values with increasing thickness of the polymer layer. The corresponding $D_{\text {out min }}$ for each thickness, marked by intersections $A, B$, and $C$ in Figure 4, are found to be $7.8 \mu \mathrm{m}, 19.8 \mu \mathrm{m}$, and $42.3 \mu \mathrm{m}$, respectively.

Since the molar mass of the PVPh used in this experiment $(11000 \mathrm{~g} / \mathrm{mol})$ is lower than its entanglement molar mass $M_{\mathrm{e}}$, which is reported to be $29300 \mathrm{~g} / \mathrm{mol},{ }^{26}$ dissolution of the polymer is favored. ${ }^{27}$ Polymer dissolution is postulated to involve solvent diffusion, during which solvent diffuses into the polymer resulting in plasticization of it and with some intermediate layers in between the still solid material and where chain disentanglement results in complete polymer dissolution. ${ }^{28}$ However, in our case, there is a thin polymer layer of several microns only and the solvent drop is rather big (on the order of several tens of microns). The transition layer thickness is, therefore, believed to be negligible both because the experimental temperature (room temperature) is well below the glass transition temperature $\left(T_{g}=130-185^{\circ} \mathrm{C}\right)$ when the mechanism of polymer dissolution shifts from normal dissolution to the cracking mode, where polymer blocks leave the surface in an eruption process, ${ }^{28}$ and because of the small polymer thickness. Therefore, all of the polymer is believed to be dissolved. The dissolved polymer is transported to the rim due to the fast evaporation of the solvent at the border of the sessile drop and the replenishment of the solvent from the center to the border, as a result of the pinned contact line of the droplet, leading to the accumulation of dissolved material at the rim. This is known as the coffee stain effect. ${ }^{16-19}$ The pinning is supported by a very small initial contact angle of the solvent droplet on the PVPh surface, calculated to be in the range of $8^{\circ}-14^{\circ}$. Even if several drops were deposited at the same place, there is only minor recovery of the polymer in the middle of the structure because the evaporation is very fast, in contrast to the observations of other researchers. ${ }^{1,2}$ Accordingly, a relatively flat inner part of the structures indicating complete removal of the polymer was found.

In summary, the effect of outer diameter and polymer thickness on polymer penetration is established for etching via holes in polymer thin films using inkjet printing in this paper. The two factors are important and can affect via hole penetration because both determine the volume of the via holes. Therefore, factors that have effect on $D_{\text {out }}$ or the polymer thickness, such as droplet diameter, temperature and polymer surface conditions, will influence via hole penetration. This is investigated in this paper based on the assumption that a through hole can be formed first instead of any other complicated drying patterns, for example, a protrusion, where other factors such as the polymer molar mass and solvent type may be more important. Both the penetration depth and the size evolution of the via hole with $N_{d}$ are important for the evaluation of inkjet printing as a via hole etching technique in polymer dielectric materials. Further work on modelling can be useful to quantitatively investigate the penetration depth, thereby predicting the penetration limit for a certain solvent droplet of a specific volume in a particular polymer layer.

The first author would like to acknowledge the full scholarship awarded by Wolfson School of Mechanical and Manufacturing Engineering in Loughborough University.

${ }^{1}$ E. Bonaccurso, H. J. Butt, B. Hankeln, B. Niesenhaus, and K. Graf, Appl. Phys. Lett. 86, 124101 (2005).

${ }^{2}$ S. Karabasheva, S. Baluschev, and K. Graf, Appl. Phys. Lett. 89, 031110 (2006).

${ }^{3}$ H. M. Haverinen, R. A. Myllylä, and G. E. Jabbour, Appl. Phys. Lett. 94, 073108 (2009).

${ }^{4}$ Y. J. Xia and R. H. Friend, Appl. Phys. Lett. 90, 253513 (2007).

${ }^{5}$ C. Sele, T. von Werne, R. Friend, and H. Sirringhaus, Adv. Mater. 17, 997 (2005).

${ }^{6}$ Y. Nobusa, Y. Yomogida, S. Matsuzaki, K. Yanagi, H. Kataura, and T. Takenobu, Appl. Phys. Lett. 99, 183106 (2011).

${ }^{7}$ G. L. Whiting and A. C. Arias, Appl. Phys. Lett. 95, 253302 (2009).

${ }^{8}$ S. Gamerith, A. Klug, H. Scheiber, U. Scherf, E. Moderegger, and E. List, Adv. Funct. Mater. 17, 3111 (2007).

${ }^{9}$ D. Kim, S. Jeong, B. K. Park, and J. Moon, Appl. Phys. Lett. 89, 264101 (2006).

${ }^{10}$ S. Jeong, K. Woo, D. Kim, S. Lim, J. S. Kim, H. Shin, Y. Xia, and J. Moon, Adv. Funct. Mater. 18, 679 (2008).

${ }^{11}$ M. Neophytou, W. Cambarau, F. Hermerschmidt, C. Waldauf, C. Christodoulou, R. Paciso, and S. A. Choulis, Microelectron. Eng. 95, 102 (2012).

${ }^{12}$ S. H. Ko, H. Pan, C. P. Grigoropoulos, C. K. Luscombe, J. M. J. Fréchet, and D. Poulikakos, Nanotechnology 18, 345202 (2007).

${ }^{13}$ J.-P. Lu, F.-C. Chen, and Y.-Z. Lee, J. Disp. Technol. 5, 162 (2009).

${ }^{14}$ Y. S. Yang, I.-K. You, J. B. Koo, S. S. Lee, S. C. Lim, and S. Y. Kang, J. Korean Phys. Soc. 57, 1699 (2010).

${ }^{15}$ T. Kawase, T. Shimoda, C. Newsome, H. Sirringhaus, and R. H. Friend, Thin Solid Films 438-439, 279 (2003). 
${ }^{16}$ T. Kawase, H. Sirringhaus, R. H. Friend, and T. Shimoda, Adv. Mater. 13, 1601 (2001).

${ }^{17}$ R. D. Deegan, Phys. Rev. E 61, 475 (2000).

${ }^{18}$ R. D. Deegan, O. Bakajin, T. F. Dupont, G. Huber, S. R. Nagel, and T. A. Witten, Nature 389, 827 (1997).

${ }^{19}$ R. D. Deegan, O. Bakajin, T. F. Dupont, G. Huber, S. R. Nagel, and T. A. Witten, Phys. Rev. E 62, 756 (2000).

${ }^{20}$ B. J. de Gans, S. Hoeppener, and U. S. Schubert, Adv. Mater. 18, 910 (2006).

${ }^{21}$ B. J. de Gans, S. Hoeppener, and U. S. Schubert, J. Mater. Chem. 17, 3045 (2007).
${ }^{22}$ Y. J. Xia and R. H. Friend, Appl. Phys. Lett. 88, 163508 (2006).

${ }^{23}$ Y. Zhang, C. Liu, and D. C. Whalley, J. Phys. D: Appl. Phys. 45, 125303 (2012).

${ }^{24}$ I. A. Grimaldi, A. De Girolamo Del Mauro, G. Nenna, F. Loffredo, C. Minarini, and F. Villani, J. Appl. Polym. Sci. 122, 3637 (2011).

${ }^{25}$ A. J. Lennon, A. W. Y. Ho-Baillie, and S. R. Wenham, Sol. Energy Mater. Sol. Cells 93, 1865 (2009).

${ }^{26}$ F. Lapointe, M. Pézolet, and J. Brisson, Polymer 48, 5626 (2007).

${ }^{27}$ G. Li, K. Graf, E. Bonaccurso, D. S. Golovko, A. Best, and H. J. Butt, Macromol. Chem. Phys. 208, 2134 (2007).

${ }^{28}$ B. A. Miller-Chou and J. L. Koenig, Prog. Polym. Sci. 28, 1223 (2003). 